\title{
PEER INSTRUCTION: METODOLOGIA ATIVA DE ENSINO E APRENDIZAGEM E SUAS FERRAMENTAS DE INTERATIVIDADE GRATUITAS
}

Carla Plantier Message, Ana Paula Ambrósio Zanelato Marques, Raquel Rosan Christino Gitahy, Sidinei de Oliveira Sousa, Adriana Aparecida de Lima Terçariol

Universidade do Oeste Paulista - UNOESTE, Mestrado em Educação, Presidente Prudente, SP. E-mail: caplantier@gmail.com.

\section{RESUMO}

Uma aula somente expositiva como no ensino tradicional, para estudantes das novas gerações não explora todas as potencialidades, visto que a informação encontra-se disponível ao realizar uma busca na internet. As metodologias ativas possuem ênfase nos estudantes, e assim mais condizentes com essa geração. O presente artigo apresenta a metodologia ativa Peer Instruction (PI) e suas ferramentas de interatividade, com foco nas soluções gratuitas. Foi realizado um levantamento, a partir de pesquisa bibliográfica, de ferramentas de interatividade gratuitas que possam auxiliar na aplicação da metodologia Peer Instruction. Concluímos que o PI com suas ferramentas de interatividade gratuitas facilita o trabalho do professor através de feedback imediato e possibilita autonomia e trabalho colaborativo entre os estudantes.

Palavras-chave: Peer Instruction, Metodologia Ativa, Ferramentas de Interatividade Gratuitas, Educação, Tecnologia.

\section{PEER INSTRUCTION: ACTIVE TEACHING AND LEARNING METHODOLOGY AND ITS FREE INTERACTIVITY TOOLS}

\begin{abstract}
A lecture-only lecture as in traditional teaching, for students of the new generations does not exploit all the potential, since the information is available when searching the internet. The active methodologies have an emphasis on the students, and thus more appropriate this generation. This article presents the active methodology Peer Instruction (PI) and its interactivity tools, focused on the free tools. A survey was carried out, based on bibliographical research, of free interactivity tools that could aid in the application of the Peer Instruction methodology. We conclude that the IP with its free interactivity tools facilitates the teacher's work through immediate feedback and allows autonomy and collaborative work among the students.
\end{abstract}

Keywords: Peer Instruction, Active Methodology, Free Interactivity Tools, Education, Technology. 


\section{INTRODUÇÃO}

Atualmente boa parte da disseminação das informações é realizada com o uso das tecnologias digitais da informação e comunicação (TDIC). É notório que com o advento da internet e a facilidade do seu uso, é cada vez mais comum a presença e a utilização pelas novas gerações, assim ela é responsável por boa parte das buscas por informações. Como as novas gerações possuem fácil acesso à internet, consequentemente, possuem acesso a informações sobre qualquer tema ou assunto num simples acesso à rede. Sobre esse fato Dias (2016, p.01) considera:

Todo o aparato tecnológico que povoa o universo dessas gerações faz com que o professor repense a sua práxis educativa. A relação professor $x$ aluno configurada em falar $x$ ouvir não tem mais sentido para essas gerações. É necessário atualizar a metodologia utilizada, as relações, as práticas, enfim, é necessário pensar no processo ensino aprendizagem de maneira mais colaborativa e motivadora, onde o aluno é o centro desse processo.

Desta forma, aulas tradicionais, nas quais professores simplesmente transmitem seu conhecimento aos estudantes, não são tão atrativas para essa nova geração, que possuem a informação num simples acesso. Moran (2013) relata que métodos tradicionais onde o professor é o transmissor do conhecimento tinham nexo quando a informação era inacessível por outros meios.

É preciso envolver os estudantes e instigar o seu aprender a aprender, para isso existem as metodologias ativas, por meio das quais o professor passa de transmissor para o de mediador do aprender dos estudantes. Sobre metodologias ativas Borges e Alencar (2014, p.120) afirmam:

Podemos entender Metodologias Ativas como formas de desenvolver o processo do aprender que os professores utilizam na busca de conduzir a formação crítica de futuros profissionais nas mais diversas áreas. A utilização dessas metodologias pode favorecer a autonomia do educando, despertando a curiosidade, estimulando tomadas de decisões individuais e coletivas, advindos das atividades essenciais da prática social e em contextos do estudante.

Sobre metodologias ativas Dias (2016, p.02), afirma que são seus atributos:

- Centradas no aluno;

- Envolvem métodos e técnicas que estimulam a interação aluno $x$ professor, aluno $\mathrm{x}$ aluno e aluno $\mathrm{x}$ material didático e outros recursos de aprendizagem.

- Opõem-se a métodos e técnicas que enfatizam a transmissão do conhecimento.

- Têm como bases teóricas:

- Sócio construtivismo;

- Psicologia cognitiva;

- Teoria cognitiva social;

- Aprendizagem baseada na reflexão;

- Aprendizagem colaborativa e significativa;

- Reflexão crítica sobre a experiência;

- Maior apropriação e divisão das responsabilidades no processo de ensino-aprendizagem;

- Desenvolvimento de capacidade para autoaprendizagem; 
- Favorece uma maior retenção do conhecimento;

- Produz melhoria no relacionamento interpessoal.

Existem várias metodologias ativas de ensino e aprendizagem, como por exemplo, Sala de Aula Invertida, PBL - Problem Based Learning (Aprendizagem baseada em problemas), TBL - Team Based Learning (Aprendizagem baseada em times), PI - Peer Instruction (Instruções pelos pares), PBL - Project Based Learning (Aprendizagem baseada em projetos), Estudos de Casos, Seminários, entre outras.

Apresentar-se-á nesse artigo a metodologia ativa Peer Instruction, seus conceitos, características e algumas ferramentas de interatividade gratuitas para otimizar sua utilização.

\section{METODOLOGIA}

Para a realização deste estudo foram utilizados procedimentos metodológicos próprios das pesquisas bibliográficas. Através da investigação bibliográfica, considerada por Vergara (1998, $p$. 46), como aquela que "é estudo sistematizado desenvolvido com base em material publicado em livros, revistas, jornais, redes eletrônicas, isto é, material acessível ao público em geral", com base na qual foi empreendida a revisão de literatura que possibilitou a fundamentação teórica sobre a temática do estudo.

\section{DISCUSSÃO}

A metodologia Peer Instruction, é uma metodologia ativa, criada na década de 90 pelo professor de Física de Harvard, Eric Mazur. Para a Peer Instruction obter êxito Mazur (2015, p.10) esclarece que:

É necessário que os livros e as aulas expositivas desempenhem papéis diferentes dos que costumam exercer em uma disciplina convencional. Primeiro, as tarefas de leitura do livro, realizadas antes das aulas, introduzem o material. A seguir, as aulas expositivas elaboram o que foi lido, esclarecem as dificuldades potenciais, aprofundam a compreensão, criam confiança e fornecem exemplos adicionais.

A Peer Instruction tem como propósito a interação e colaboração entre os estudantes nos conteúdos estudados por eles mesmos e expostos pelo professor. A aplicação pode ser realizada usando o teste conceitual, que refere-se às questões sobre o conteúdo estudado. Os materiais para estudo são disponibilizados para os estudantes previamente, extra sala de aula e durante a aula. Em sala o professor faz uma explanação rápida do conteúdo e em seguida é aplicado o teste conceitual que ocorre como mencionado por Mazur (2015), primeiramente com questões aplicadas individualmente com um tempo curto para resposta do tema estudado. $O$ professor verifica o percentual de acerto e seguindo a teoria de Mazur (2015), caso o percentual de acerto seja inferior a 30\%, o professor faz nova explicação do conteúdo. Se o percentual de acerto ficar na faixa de $30 \%$ à $70 \%$, o professor solicita que os estudantes discutam em grupos, assim os estudantes tentam convencer seus colegas em poucos minutos para que voltem a responder a mesma questão. Finalmente se o percentual de acerto for maior que $70 \%$, seguem para a próxima questão.

Ainda de acordo com Mazur (2015), muitas vezes os estudantes ensinam os conteúdos entre si de forma mais eficiente que o próprio professor, isso pelo fato de que acabaram de aprender e sabem das dificuldades que encontraram para entender. 
Para realizar a verificação do percentual de acerto das questões respondidas pelos estudantes, existem algumas maneiras. O levantamento dos acertos pode ser feito manualmente, ou com o auxílio de alguma ferramenta de interatividade. Uma das maneiras manuais de fazer a verificação é com o uso de placas impressas com as alternativas para resposta $(A, B, C, D, E)$, outra maneira, mais simples e também manual é usando as mãos, onde os estudantes levantam as mãos e mostram a quantidade de dedos de acordo com a alternativa, exemplo, se a escolha for alternativa $A$, mostram um dedo, se for alternativa $B$, mostram dois dedos e assim por diante.

A forma manual de fazer esse levantamento não auxilia o professor, o feedback é mais demorado e pode desmotivar os alunos e também erros podem ocorrer na contagem, pois é feito sem o auxílio de uma ferramenta, sem o uso de tecnologia.

O levantamento realizado por meio das ferramentas de interatividade, que podem ser gratuitas ou não, deixam a atividade mais dinâmica, pois o feedback é praticamente imediato. Essa ligeireza auxilia o docente que com mais agilidade no processo e precisão, tem em mãos se pode prosseguir com as questões, se o assunto foi aprendido pela turma ou se ele precisa intervir e proporcionar discussões entre os pares ou ainda, se precisa explanar o conteúdo para a turma.

\section{FERRAMENTAS DE INTERATIVIDADE GRATUITAS}

Para facilitar a aplicação do teste conceitual da metodologia ativa Peer Instruction as ferramentas de interatividade são de extrema importância, pela precisão e agilidade que proporcionam.

Serão apresentadas nesta seção algumas ferramentas gratuitas, pois são de fácil acesso e estão disponíveis para todos, sem custo algum. Ferramentas proprietárias, muitas vezes, inviabilizam sua aquisição e a otimização do processo de Peer Instruction. Para o uso dessas ferramentas de interatividade gratuitas são necessários computadores ou smartphones e acesso à internet. Abaixo algumas das ferramentas de interatividade usadas para auxiliar no desenvolvimento da metodologia Peer Instrucion.

Google Forms

É possível montar questionários com o uso da ferramenta gratuita da Google (Figura 1). A ferramenta possibilita responder a um questionário criado pelo professor, que por sua vez permite dar um retorno ao professor em tempo real. O Google Forms também pode exibir gráficos estatísticos das respostas dadas às questões.

Figura 1. Formulário Google Docs

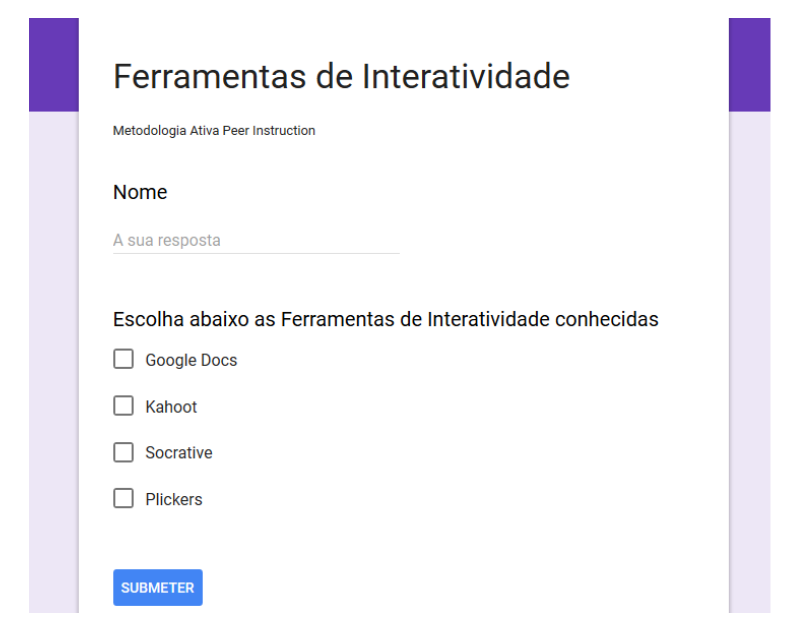


Plickers

Permite fazer questionários na sala de aula sem a obrigação de usar dispositivos por parte dos estudantes. Cada estudante recebe um cartão em papel (Figura 2) e usa seu smartphone para digitalizar o cartão e verificar as respostas dadas.

Figura 2. Cartão em papel Plickers

Fonte: https://www.plickers.com/cards
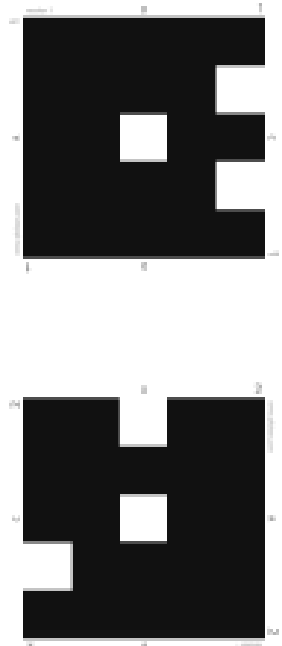

\section{Socrative}

Ferramenta que possui versão para o professor e versão para o estudante. Pode ser usado online ou baixar o aplicativo Socrative (Figura 3) no smartphone. O professor cria uma sala de aula na ferramenta e seus questionários, após a criação, deverá passar aos estudantes o código da sala de aula para que eles possam fazer acesso. Permite a conexão da turma com o professor com questionários e jogos e possui feedback imediato.

Figura 3. Tela do Principal do Socrative

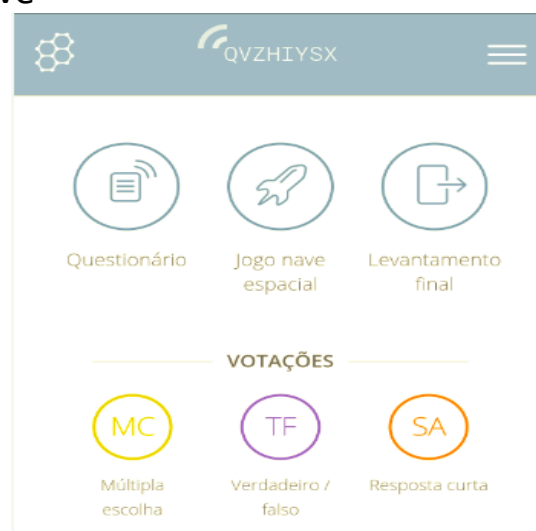


Kahoot

Serviço online similar ao Socrative, permite a criação de questionários e jogos do tipo quiz. O docente entra no site getkahoot.com para criar seu questionário, após criar o questionário, também será gerado um código, chamado Game PIN, esse deve ser disponibilizado aos estudantes para que tenham acesso às questões. O Kahoot (Figura 4) assim como o Socrative, pode ser usado online ou ter o aplicativo instalado no smartphone.

Figura 4. Tela de acesso aplicativo Kahoot

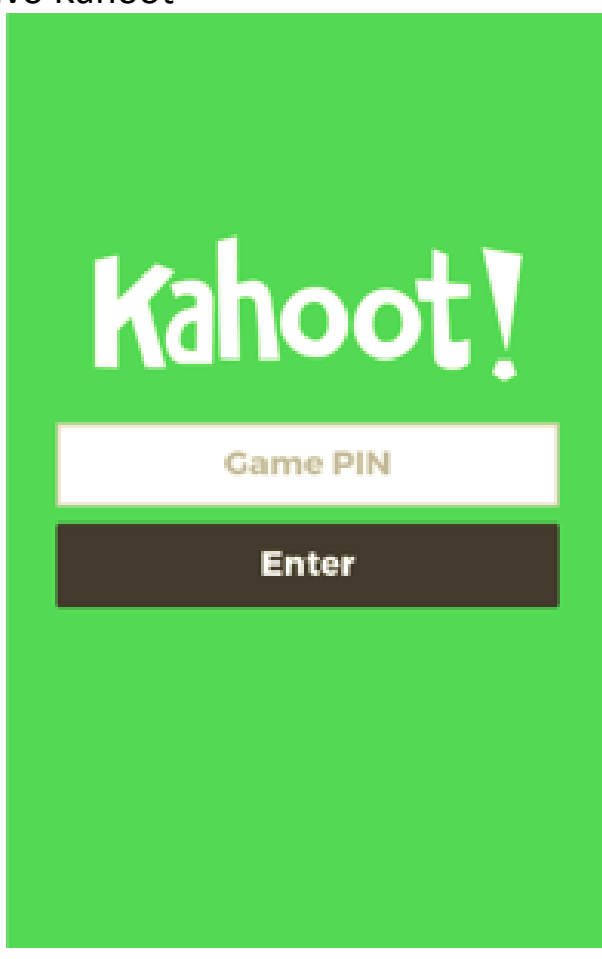

Fonte: https://www.socrative.com

Essas são algumas ferramentas de interatividade gratuitas que podem ser usadas com a metodologia ativa Peer Instruction para poder inovar e diversificar a educação. Essas ferramentas auxiliam o professor em tomadas de decisão sobre conteúdo abordado em aula. Ajudam as aulas se tornarem mais atrativas e mais dinâmicas para os estudantes.

\section{CONCLUSÃO}

Discorremos nesse artigo as necessidades de novas metodologias de aprendizagem na educação, que coloquem os estudantes como protagonista do processo de aprendizagem e o professor como um mediador para o aprendizado. A metodologia ativa de aprendizagem Peer Instruction foi apresentada, com suas características e explicitando o passo a passo para sua aplicação, bem como a apresentação de algumas ferramentas de interatividade gratuitas que auxiliam na aplicação do Peer Instruction. Consideramos que a importância das ferramentas consistem na agilidade em dar o feedback ao professor e na motivação dos estudantes em participar utilizando tecnologia nas suas aulas.

A Peer Instruction, assim como outras metodologias ativas, vem tornando o ensino e a aprendizagem mais colaborativos, com o trabalho com os colegas, em pares, motivando os alunos em seu aprendizado. Espera-se que com tais conquistas os estudantes possam ser mais críticos e reflexivos. Como a metodologia prevê o estudo extra sala do conteúdo, espera-se que os estudantes tenham maior compreensão dos temas estudados em sala, o que vai agregar nas 
discussões com os colegas. Dessa forma, a metodologia torna o ensino e a aprendizagem mais instigante, pois tem-se muitos desafios a cumprir.

\section{REFERÊNCIAS}

BORGES,T.S.;ALENCAR, G. Metodologias Ativas na Promoção da Formação Crítica do Estudante: O Uso das Metodologias Ativas como Recurso Didático na Formação Crítica do Estudante do Ensino Superior. Disponível em:<

http://www.cairu.br/revista/arquivos/artigos/2014_2/08\%20METODOLOGIAS\%20ATIVAS\%20NA\% 20PROMOCAO\%20DA\%20FORMACAO\%20CRITICA\%20DO\%20ESTUDANTE.pdf >. Acesso em: 28 jul de 2017.

DIAS, M.M. Metodologias Ativas: Parte 1. Disponível em <http://ned.unifenas.br/blogtecnologiaeducacao/educacao/metodologias-ativas-parte-1/>. Acesso em: 20 jul. 2017.

Google Forms. Disponível em:

https://docs.google.com/forms/d/1iHUjwQ9MzYzrxsuRWAM7SOd1klqCib16v4qLaMv7nzY/edit>. Acesso 01 aug. 2017.

Kahoot. Disponível em:<http://kahoot.com>. Acesso em: 01 aug. 2017.

MAZUR, Eric. Peer Instruction: a revolução da aprendizagem ativa. Porto Alegre: Penso, 2015.

MORAN, J. Mudando a Educação com Metodologias Ativas. Disponível em <http://www2.eca.usp.br/moran/wp-content/uploads/2013/12/mudando_moran.pdf>. Acesso em: 31 jul. 2017.

Plickers. Disponível em: <https://www.plickers.com/>. Acesso em: 01 aug. 2017.

Socrative. Disponível em : <http://socrative.com>. Acesso em: 01 aug. 2017.

VERGARA, Sylvia Constant. Projetos e relatórios de pesquisa em administração. São Paulo: Atlas, 1998. 